\title{
Vaccine preventable diseases in palliative treated children - Report of the PalliVac study group
}

Holger Hauch $^{1}$, Irina Tretiakova ${ }^{2}$, Jens Kaestner ${ }^{3}$, Peter Brundner ${ }^{4}$, Mario Scheer $^{5}$, Astrid Kimmig ${ }^{6}$, Andrea Hagenguth ${ }^{7}$, Vera Vaillant ${ }^{1}$, Cho Ming Chao ${ }^{8}$ and Daniel Berthold ${ }^{8}$

${ }^{1}$ University Children`s Hospital Giessen, Palliative Care Team for Children, Giessen, Hesse, Germany

${ }^{2}$ Klinikum Bad Hersfeld, Academic Children’s Hospital, Bad Hersfeld, Hesse, Germany

${ }^{3}$ University Children`s Hospital Jena, Palliative Care Team for Children, Jena, Thuringia, Germany

${ }^{4}$ Children's Hospice Service Saar, Palliative Care Team, Merchweiler, Saarland, Germany

${ }^{5}$ Children's Hospice Service Syke, Palliative Care Team, Syke, Lower Saxony, Germany

${ }^{6}$ University Children`s Hospital Tübingen, Palliative Care Team for Children, Tübingen, Baden-Wuerttemberg, Germany

${ }^{7}$ German Red Cross, Heinrich-Schwesternschaft e.V., Palliative Care Team, Kiel, Schleswig-Holstein, Germany

${ }^{8}$ University Hospital Giessen, Palliative Care Team for Adults, Giessen, Hesse, Germany

\begin{abstract}
Context: In Germany, 33 pediatric specialized home palliative care (SHPC) teams provide support for children with life-limiting diseases. In 2017, a 12-year old, not vaccinated boy with severe delay of neurological development suffered from varicella infection with severe deterioration of general condition and dyspnea due to a pneumonia. According to our knowledge this was the first reported SHPC patient with a vaccine preventable disease (VPD) so far.

Methods: Retrospective analysis of other VPD cases. All physicians of SHPC and hospices are asked to complete to a questionnaire.

Results: 34 physicians (32 SHPC and 2 hospices) answered. Overall, 25 patients with a diagnosed VPD (group 1) were reported. The most frequent VPDs were influenza (44\%), varicella (16\%) followed by one case of diphtheria, hepatitis A/B, measles, meningococci, pertussis, pneumococci, rotavirus, respiratory syncytial virus (RSV), and rubella. Suspicions of VPDs (group 2) were reported in another 22 cases. Influenza (56\%), pertussis (14\%), rotavirus (14\%) followed by one case of meningococci, measles, RSV and varicella with one case each. Severe symptoms like dyspnea and deterioration of general health occurred in both groups. Main complications were admission to intensive care unit (ICU) in $21,3 \%$, ventilation in $14,9 \%$, death in $4,3 \%$ and infection of a health care professional in $10,6 \%$. Physicians agreed it could be helpful to prevent VPD.
\end{abstract}

Conclusion: VPDs appear to play a certain role in SHPC in Germany. They can cause distressing symptoms up to ICU treatment and death. Further investigations are warranted.

Abbreviations: ACT: Association for Children with Lifethreatening or Terminal Conditions and their Families, SHPC: Specialized Home Palliative Care, VPD: Vaccine Preventable Disease

\section{Introduction}

Palliative care for children and adolescents can be conducted at home [1]. In Germany, 33 specialized home palliative care (SHPC) teams for children provide support for patients and family members [2]. In 14 of 16 German states children and adolescents have access to SHPC, already.

This research was triggered by an individual patient in the care of our specialized home palliative care team (SHPC). This 12-year old boy with neurodegenerative disease was treated in a specialized nursing home. He was not vaccinated because of his parent's decision. He was infected with varicella, probably from a child that had visited another patient. Our patient developed skin rash, pneumonia, dyspnea and neurological deterioration. Unfortunately, after a short interims period of improvement, he died due to a respiratory failure. This has been the first reported case of a vaccine preventable disease (VPD) in a palliative treated child to our experience so far.
In Germany, Robert Koch Institute (RKI) and the vaccination commission (STIKO) publish regular vaccine recommendations [3]. There is a common misperception that such recommendations are irrelevant in the setting of palliative care. However, in SHPC, the one year-survival rate is between 35 and $78 \%[1,4]$ and the number of patients is increasing. To our knowledge there are neither similar cases nor data of vaccination coverage rate of palliative treated patients. Thus, it appeared to us timely to create data to allow an overview of the frequency of similar cases as our patient, and to initiate a discussion regarding the value of vaccinations in pediatric SHPC.

${ }^{\star}$ Correspondence to: Holger Hauch, Palliative Care Team for Children, Justus Liebig University of Giessen, Klinikstraße 33, 35392 Giessen, Hesse, Germany, Tel: +49-641-98543907, Fax: +49-641-98543988; E-mail: holger.hauch@paediat. med.uni-giessen.de

Key words: specialized home palliative care, children, adolescents, vaccination, infection

Received: April 15, 2020; Accepted: April 28, 2020; Published: May 01, 2020 


\section{Methods}

Physicians of all German pediatric SHPC teams and hospices were asked to complete a questionnaire. Answers could be given with the online software "LimeSurvey" (LimeSurvey GmbH, Hamburg, Germany) or written on a paper form. All information given were in an anonymous form. The questionnaire included medical information of similar patients grouped as cases of proved (group 1) or suspected VPD (group 2). The severity of associated symptoms and complications was graded in on a Likert scale $(1=$ minimal symptom level to $5=$ maximal symptom level). The questionnaire also contained the original diagnosis causing the palliative situation, sex and age as well as questions to assess the relevance of the research topic: physicians were asked to estimate the need of further information and their personal opinion on the possible options of vaccinating children with life-limiting diseases. Finally, their overall experience in pediatric palliative care was asked. Statistical analyses were conducted using SPSS (Statistical Package for Social Studies, version 23.0, IBM incorporation) and included descriptive statistics and nonparametric Wilcoxon test. The study was approved by local ethical commission (Justus Liebig University AZ 133/18) registered to the German register for clinical studies (= DRKS) [5], (ID: DRKS00015045).

\section{Results}

We approached all 33 German pediatric SHPC managing physicians known to provide similar care and 16 pediatric hospices by email. 28 SHPC teams $(84,8 \%)$ and 2 physicians of hospices [6] $(12,5 \%)$ answered. Mean experience in palliative care was 7,5 years $( \pm$ $5,1 \mathrm{SD})$ for both groups. 25 patients with proven VPD (= group 1) and 22 patients with suspected VPD (= group 2 ) were reported. There was no statistical difference in age, sex and ACT group (Table 1) between both groups [7]. In group 1, the most frequent infections were influenza (44\%) and varicella (16\%) followed by a broad spectrum of single infections (Figure 1). The diagnoses (multiple response possible) were made clinically in 64,7\%, using direct detection methods (PCR and/or agglutination methods) in $58,8 \%$, and serological testing in $29,4 \%$. In group 2, the most frequent infections were influenza (56\%), followed by pertussis and rotavirus ( $14 \%$ each) (Figure 1). When comparing the two groups there were no difference in complications or severity of symptoms. Therefore, these data were aggregated and analyzed together.

Severity of symptoms were statistically not normally distributed. In descriptive analysis median and quartiles (25. and 75. quantile respectively) were calculated. All patients suffered from moderate to severe symptoms, including fever (median 4,0/Q25: 3,0; Q75: 4,0) and deterioration of general condition (median 4,5/Q25: 3,25; Q75: 5,0) for all patients. Almost all patients (45/47) suffered from dyspnea reported between uncomfortable and intense (median 4,0/Q25: 1,0; Q75: 5,0). Worsening of neurological symptoms was reported in most patients (35/47 cases) with a median value of 1,5 (Q25: 1,0; Q75: 3,75). Pain was less common and reported in 28/47 cases with a median of 1,5 (Q25: 1,0; Q75: 3,0) (Table 2).

Complications were reported in 34 patients: 10 patients were admitted to the hospital (all of those to the ICU); 7 patients with life limiting diseases were ventilated and 2 died due to VPD. Physicians also reported events occurring in other persons as "complications": 5 members of SHPC team reported a suspected infection (all cases with influenza) due to contact to the patient.

Asking for the attitude to vaccination in SHPC patients all replying caregivers were of the opinion, vaccination should play moderate to great role in palliative care (Table 3 ). $75 \%$ of colleagues agreed that the vaccination status of family members of the patients should be taken

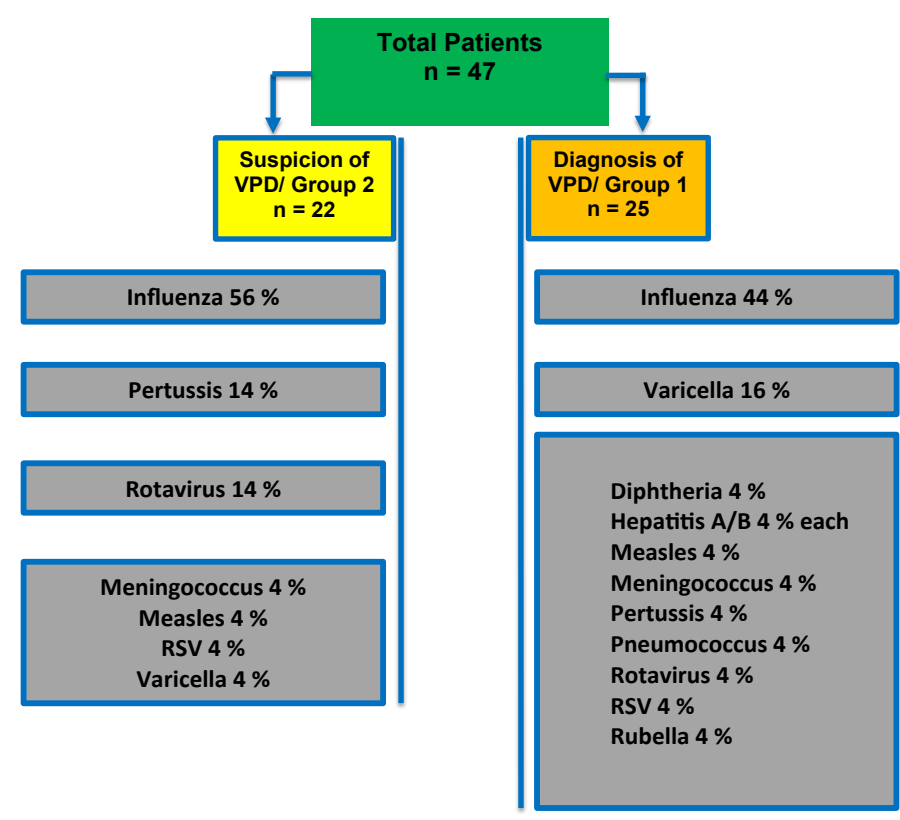

Figure 1. Distribution of proven and suspected VPD.

Table 1. Distribution of gender, age and ACT group, and the methods used to diagnose VPD in both groups.

\begin{tabular}{|c|c|c|c|c|}
\hline Patients (n) & $\operatorname{Sex}(\%)$ & $\begin{array}{l}\text { Age (years) } \\
\text { Mean }( \pm \text { SD) }\end{array}$ & $\begin{array}{l}\text { ACT-group } \\
(\%)\end{array}$ & $\begin{array}{l}\text { (suspected) diagnosis made } \\
\text { (\%), Multiple responses }\end{array}$ \\
\hline $\begin{array}{l}\text { Group } 1 \\
\mathrm{~N}=25\end{array}$ & $\begin{array}{l}12 \mathrm{f}(48 \%) \\
13 \mathrm{~m} \mathrm{(52 \% )}\end{array}$ & $7,5( \pm 5,1)$ & $\begin{array}{l}1: 1(4 \%) \\
2: 0(0 \%) \\
3: 13(52 \%) \\
4: 11(44 \%)\end{array}$ & $\begin{array}{l}\text { clinical diagnosis } 64,7 \% \\
\text { serologic testing } 29,4 \% \\
\text { PCR-testing } 58,8 \%\end{array}$ \\
\hline $\begin{array}{l}\text { Group } 2 \\
\mathrm{~N}=22\end{array}$ & $\begin{array}{l}10 \mathrm{f}(45 \%) \\
12 \mathrm{~m}(55 \%)\end{array}$ & $6,9( \pm 4,2)$ & $\begin{array}{l}1: 1(5 \%) \\
2: 0(0 \%) \\
3: 12(55 \%) \\
4: 9(40 \%)\end{array}$ & clinical suspicion \\
\hline
\end{tabular}

Table 2. It shows the median degree of severity of distressful symptoms of VPDs (Likertscale, minimum $=1$, maximum of severity $=5, Q 25=25$. quantile, $Q 75=75$. quantile).

\begin{tabular}{|l|l|}
\hline Symptoms & $\begin{array}{l}\text { Frequency reported } \\
\text { Median/Q25 and Q75 }\end{array}$ \\
\hline $\begin{array}{l}\text { Fever } \\
\text { (min. }=1 \text { to max. }=5)\end{array}$ & $\begin{array}{l}\mathrm{N}=47 \\
\text { Median 4,0 (Q25: 3,0; Q75: 4,0) }\end{array}$ \\
\hline $\begin{array}{l}\text { Deterioration of general condition } \\
\text { (min. }=1 \text { to max. }=5)\end{array}$ & $\begin{array}{l}\mathrm{N}=47 \\
\text { Median 4,5 (Q25: 3,25; Q75: 5,0) }\end{array}$ \\
\hline $\begin{array}{l}\text { Dyspnea } \\
\text { (min. }=1 \text { to max. }=5)\end{array}$ & $\begin{array}{l}\mathrm{N}=45 \\
\text { Median 4,0 (Q25: 1,0; Q75: 5,0) }\end{array}$ \\
\hline $\begin{array}{l}\text { Worsening of neurologic symptoms } \\
\text { (min. }=1 \text { to max. }=5)\end{array}$ & $\begin{array}{l}\mathrm{N}=35 \\
\text { Median } 1,5(\mathrm{Q} 25: 1,0 ; \mathrm{Q} 75: 3,75)\end{array}$ \\
\hline $\begin{array}{l}\text { Pain } \\
\text { (min. }=1 \text { to } \max .=5)\end{array}$ & $\begin{array}{l}\mathrm{N}=28 \\
\text { Median } 1,5(\mathrm{Q} 25: 1,0 ; \mathrm{Q} 75: 3,0)\end{array}$ \\
\hline
\end{tabular}

Table 3. Attitude of SHPC caregivers on theoretical aspects of vaccination. It shows the extent of agreement to the statements in the questionnaire regarding vaccinating in VPDs (Likert scale $1=$ no agreement to $5=$ strong agreement, Q25 $=25$. quantile, Q75 $=75$. quantile).

\begin{tabular}{|l|l|}
\hline $\begin{array}{l}\text { Statement to vaccination in palliative } \\
\text { treated children }\end{array}$ & $\begin{array}{l}\text { Number of answering colleagues/ } \\
\text { Median (Q25 and Q75) }\end{array}$ \\
\hline $\begin{array}{l}\text { "Vaccination does not play a role in } \\
\text { palliative treated children." }\end{array}$ & $\begin{array}{l}\mathrm{N}=30 \\
\text { Median } 2,0(\mathrm{Q} 25: 1,0 / \mathrm{Q} 75: 3,0)\end{array}$ \\
\hline $\begin{array}{l}\text { "It can be useful to vaccinate palliative } \\
\text { treated children in order to prevent } \\
\text { distressing symptoms". }\end{array}$ & $\begin{array}{l}\mathrm{N}=30 \\
\text { Median 5,0 (Q25: 4,25/Q75: 5,0) }\end{array}$ \\
\hline $\begin{array}{l}\text { "A SHPC caregiver should pay more } \\
\text { attention on the vaccination status in the } \\
\text { family" }\end{array}$ & $\begin{array}{l}\mathrm{N}=30 \\
\text { Median 5,0 }(\mathrm{Q} 25: 3,0 / \mathrm{Q} 75: 5,0)\end{array}$ \\
\hline
\end{tabular}




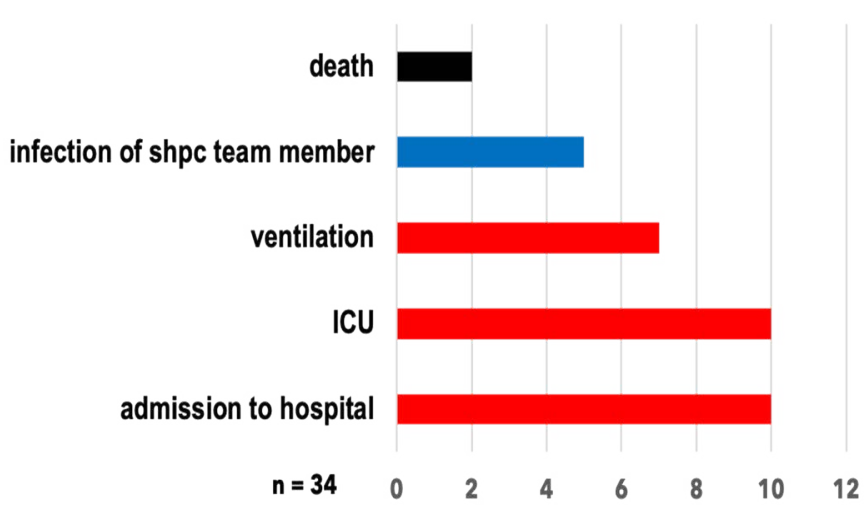

Figure 2. Complications of suspected or diagnosed VPD (absolute count).

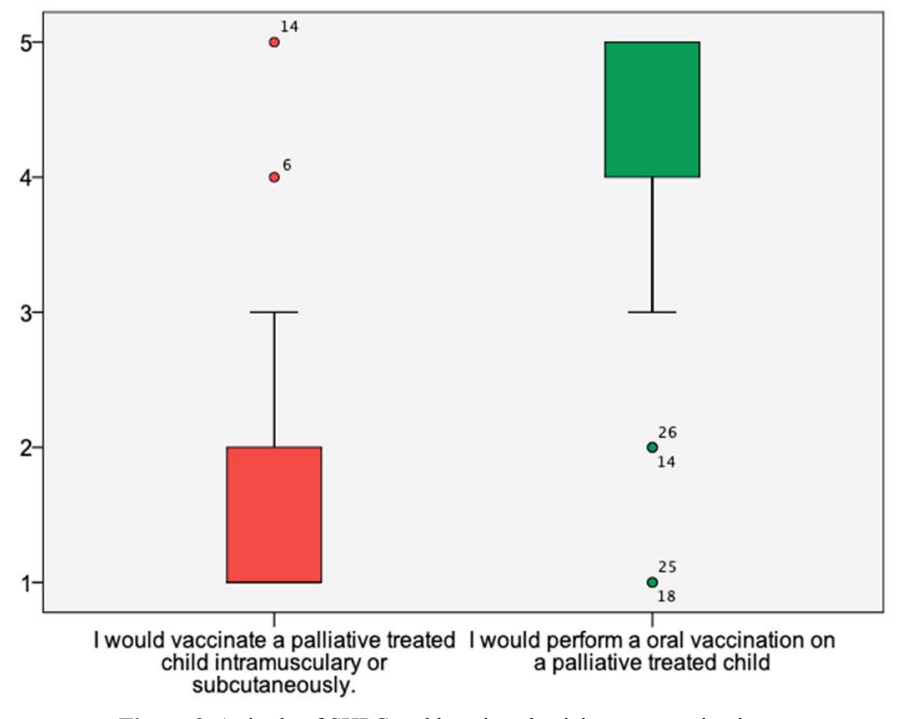

Figure 3. Attitude of SHPC and hospice physicians on vaccinations.

into consideration more than presently in the setting of SHPC. There was also a strong consensus among the answering physicians that it could be useful to prevent VPDs by vaccinating children treated with palliative intent. However, there was a statistically significant difference in this answer as the vaccination method was specified: There was a strong wish to vaccinate orally/nasally (median 5,0; Q25 4,0; Q75 5,0) but not intramuscular or subcutaneous (median 1,0; Q25 1,0; Q75 2,0 $(\mathrm{p}<0,001$, Wilcoxon test, see figure 3$)$.

\section{Discussion}

The index case of a 12-year old child with distressful symptoms due to a primary varicella infection focused the local SHPC team on the relevance of vaccination in palliative care. Since we observed a lack of published data, German SHPC teams and hospice caregivers were asked to report their experience. To our surprise, as many as 47 cases were reported and could be analyzed. Patients at "risk" seemed to be children and adolescents of ACT group 3 and 4 . These patients usually do not show a fast-progressive disease and the duration in SHPC could be even longer. Therefore, they face a higher risk of getting infected in the period of SHPC. Influenza was most frequently suspected or diagnosed (i.e. up to $78 \%$ with PCR). Influenza, a contagious infectious disease has a short mean incubation time of 2 days [8]. It is known to have a rapid transmission in crowded areas including schools and nursing homes [9]. Transmission occurs due to droplets containing viruses. The virus can also be spread by contaminated hands [10]. Protection against Influenza can be reached with personal hygiene and vaccination [6]. In principle there are live attenuated influenza vaccines, (LAIV, nasal application) and inactivated influenza vaccines, (IIV, intramuscular or subcutaneous application) available [11]. Symptoms of Influenza are fever, coughing, muscle and joint pain, severe malaise and headache.

Also, all the patients in this study developed fever, deterioration of general condition and a remarkable amount of dyspnea. SHPC teams mainly want to control symptoms and stabilize the situation at home and prevent hospitalization. Despite this goal, the ICU admission rate of $21 \%$ appears to be even higher than in patients not in palliative care. The severity of the illnesses justified the admissions: many patients were ventilated and two died. These data show that the course of VPDs in a chronically ill child can be acute and dramatic with a high risk to be a final and particularly psychological traumatic event for the family.

Opinion of a representative part of pediatric SHPC professionals showed that there is a consensus in the great need to consider vaccinations. VPDs appear to play a certain and underestimate role in pediatric palliative care in Germany. Because of the retrospective design it is not possible to calculate the incidence of VPDs in palliative treated children. The results of this survey led to formation of the PalliVac study group to initiate follow up studies. In a next step, it could be helpful to examine then coverage rate of all children in SHPC and to look at regional differences. The prospective phase of PalliVac (registered to German registry of clinical studies, ID: DRKS: 00015045) was started in January $1^{\text {st }} 2019$.

\section{Acknowledgments}

Authors are thankful to Prof. Dr. Alfred Reiter, Giessen, Germany and Dr. med. habil. Johannes E.A. Wolff, Chicago, IL, USA, for the helpful discussions and for reviewing this paper.

\section{Conflict of interest}

Authors declare that there is no conflict.

\section{Funding}

This research did not receive any specific grant from funding agencies in the public, commercial, or not-for-profit sectors.

\section{References}

1. Hauch H, Klinkel N, Chao C, Behrje J, Kreuzaler P, et al. (2016) Constitution of specialized palliative home care team in Hesse. Evaluation after one year. Klin Paediat 228: 145-148. [Crossref]

2. Kremeike K, Mohr A, Nachtmann J, Reinhardt D, Geraedts M, Sander A (2016) Evaluation of specialized palliative home care in Lower Saxony-a qualitative study of parents' view. Gesundheitswesen 78: 306-312. [Crossref]

3. German Vaccination Commission (STIKO) (2019) vaccination recommendations Available from: https://www.rki.de/DE/Content/Infekt/EpidBull/Archiv/2018/ Ausgaben/34_18.pdf?_blob=publicationFile Accessed May 21, 2019.

4. Groh G, Feddersen B, Führer M, Domenico Borasio G (2014) Specialized Home Palliative Care for Adults and Children: Differences and Similarities. J Palliat Med 17 : 803-810. [Crossref]

5. Steering Committee of the EAPC task force (2007) IMPaCCT: standards for paediatric palliative care in Europe. Eur J Pall Care 14: 109 -114. [Crossref]

6. Lester-Smith D, Zurynski YA, Booy R, Festa MS, Kesson AM, Elliott EJ (2009) The burden of childhood influenza in a tertiary paediatric setting. Commun Dis Intell $Q$ Rep 33: 209-215. [Crossref]

7. German Children's Hospice Association. Registry of German Children's Hospices Available from: https://www.deutscherkinderhospizverein.de/fileadmin/pdf/Externe Beratung/UEbersicht_stationaere_Kinderhospize_in_Deutschland_08.03.18.pdf accessed May 21, 2019. 
Hauch H (2020) Vaccine preventable diseases in palliative treated children - Report of the PalliVac study group

8. German Register for Clinical Studies. PalliVac - a multicenter, prospective study, Available from: https://www.drks.de/drks_web/navigate.do?navigationId=trial. HTML\&TRIAL_ID=DRKS00015045 Accessed May 21, 2019.

9. World Health Organization (WHO): Influenza (saisonal). Available from: https:// www.who.int/en/news-room/fact-sheets/detail/influenza-(seasonal). Accessed May 20,2019 .
10. Robert Koch Institute, Epidemiologisches Bullentin, Inluenza, Available from: https:// www.rki.de/DE/Content/Infekt/EpidBull/Archiv/2017/Ausgaben/35 17.pdf? blob=publication. File Accessed May 20, 2019.

11. Czumbel I, Quinten C, Lopalco P, Semenza JC and the ECDC expert panel working group (2018) Management and control of communicable diseases in schools and other child care settings: systematic review on the incubation period and period of infectiousness. BMC Infectious Diseases 18: 199 - 214. [Crossref]

Copyright: (C2020 Hauch H. This is an open-access article distributed under the terms of the Creative Commons Attribution License, which permits unrestricted use, distribution, and reproduction in any medium, provided the original author and source are credited. 